$08,09,11$

\title{
Выращивание щелочно-земельных галоидных сцинтилляционных кристаллов и их оптические свойства
}

\author{
() А.А. Шалаев ${ }^{1}$, А.И. Русаков ${ }^{1}$, Р.Ю. Шендрик ${ }^{1}$, А.К. Субанаков ${ }^{2}$, Ю.В. Сокольникова ${ }^{1}$, А.С. Мясникова ${ }^{1}$ \\ ${ }^{1}$ Институт геохимии им. А.П. Виноградова СО РАН, \\ Иркутск, Россия \\ ${ }^{2}$ Байкальский институт природопользования СО РАН, \\ Улан-Удэ, Россия \\ E-mail: alshal@mail.ru
}

Рассматриваются особенности выращивания кристаллов щелочно-земельных галогенидов BaBrI, BaClI и $\mathrm{SrBrI}$ методом Бриджмена. Приводятся результаты исследования сцинтилляционных характеристик выращенных кристаллов, активированных ионами европия. Было определено фактическое содержание европия в кристаллах и оценены величины световыхода и времена затухания люминесценции, приведены спектры рентгенолюминесценции и спектры поглощения полученных кристаллов.

Работа выполнена при частичной поддержке Российского научного фонда, грант РНФ 18-72-10085: спектроскопия и оптические свойства полученных кристаллов, определение концентрации европия в кристаллах, анализ полученных результатов. Выращивание кристаллов и измерение спектров рентегнолюминесценции было произведено в рамках государственного задания 0350-2016-0024. Приведенные в работе данные получены на оборудовании ЦКП „Изотопно-геохимических исследований“ ИГХ СО РАН.

DOI: 10.21883/FTT.2019.05.47588.20F

\section{1. Введение}

Последнее десятилетие одновременно с совершенствованием традиционных фторидных и оксидных сцинтилляционных систем [1] различными научно-исследовательскими группами ведется активный поиск эффективных галоидных матриц, обладающих высоким световым выходом и разрешением [2]. Из всех неорганических сцинтилляторов этого класса, выпускаемых промышленно, наилучшими характеристиками к настоящему времени обладает бромид лантана, активированный церием. Сцинтилляторы на его основе, производимые фирмой Saint-Gobain, обладают высоким световыходом (63 photons $/ \mathrm{keV})$, высоким энергетическим разрешением $(2.9 \%$, на $662 \mathrm{keV})$ и коротким временем затухания люминесценции (около $16 \mathrm{~ns}$ ). Основным недостатком этих сцинтилляторов на сегодняшний день является их высокая стоимость.

На фоне таких сцинтилляторов можно отметить перспективность систем с различными комбинациями щелочно-земельных иодидов в качестве решеткообразующих элементов, активированных редкоземельными ионами [3]. Наиболее эффективными активаторами являются двухвалентный европий, трехвалентные церий и празеодим. Так, известны работы группы Национальной лаборатории имени Лоуренса в Беркли (США) по целому ряду бинарных и тройных галогенных систем в виде мелкокристаллической порошков. Их исследование заключалось в экспрессной оценке основных сцинтилляционных характеристик с целью определения наиболее перспективных вариантов соединений для последующих разработок монокристаллических сцинтилляционных детекторов [4]. Соединения $\mathrm{BaBrI}: 8 \% \mathrm{Eu}, \mathrm{SrClI}: 5 \% \mathrm{Eu}$, $\mathrm{CsBa}_{2} \mathrm{I}_{5}: 4 \% \mathrm{Eu}$ показали высокий световыход, однако их монокристаллические образцы оптимальных размеров для спектральных исследований так и не удалось получить [3].

Существенным недостатком такого класса сцинтилляторов является их гигроскопичность. Данное свойство усложняет процесс подготовки исходных материалов, так как необходима тщательная многоступенчатая просушка шихты для выращивания кристаллов. Кроме того, требуется проведение определенных технологических процедур для обработки полученных кристаллов перед эксплуатацией. Эту проблему можно решить герметизацией гигроскопических кристаллов в специальных корпусах, подобных тем, которые используются для упаковки классических сцинтилляционных детекторов $\mathrm{NaI}(\mathrm{Tl})$.

Помимо всего прочего, данным кристаллам свойственно анизотропное тепловое расширение [5], что служит причиной их растрескивания в процессе роста и последующего охлаждения. Поэтому выбор параметров, таких как температурный градиент, скорость выращивания и режимы отжига полученного кристалла требуют особого внимания.

В данной работе представлена методика выращивания кристаллов щелочно-земельных галогенидов, активированных ионами европия и рассматриваются их основные сцинтилляционные свойства.

\section{2. Методика эксперимента и обсуждение результатов}

Кристаллы BaBrI, BaClI и SrBrI обладают орторомбической кристаллической структурой типа $\mathrm{PbCl}_{2}$ [6]. Ионы европия в этих соединениях замещают ионы 

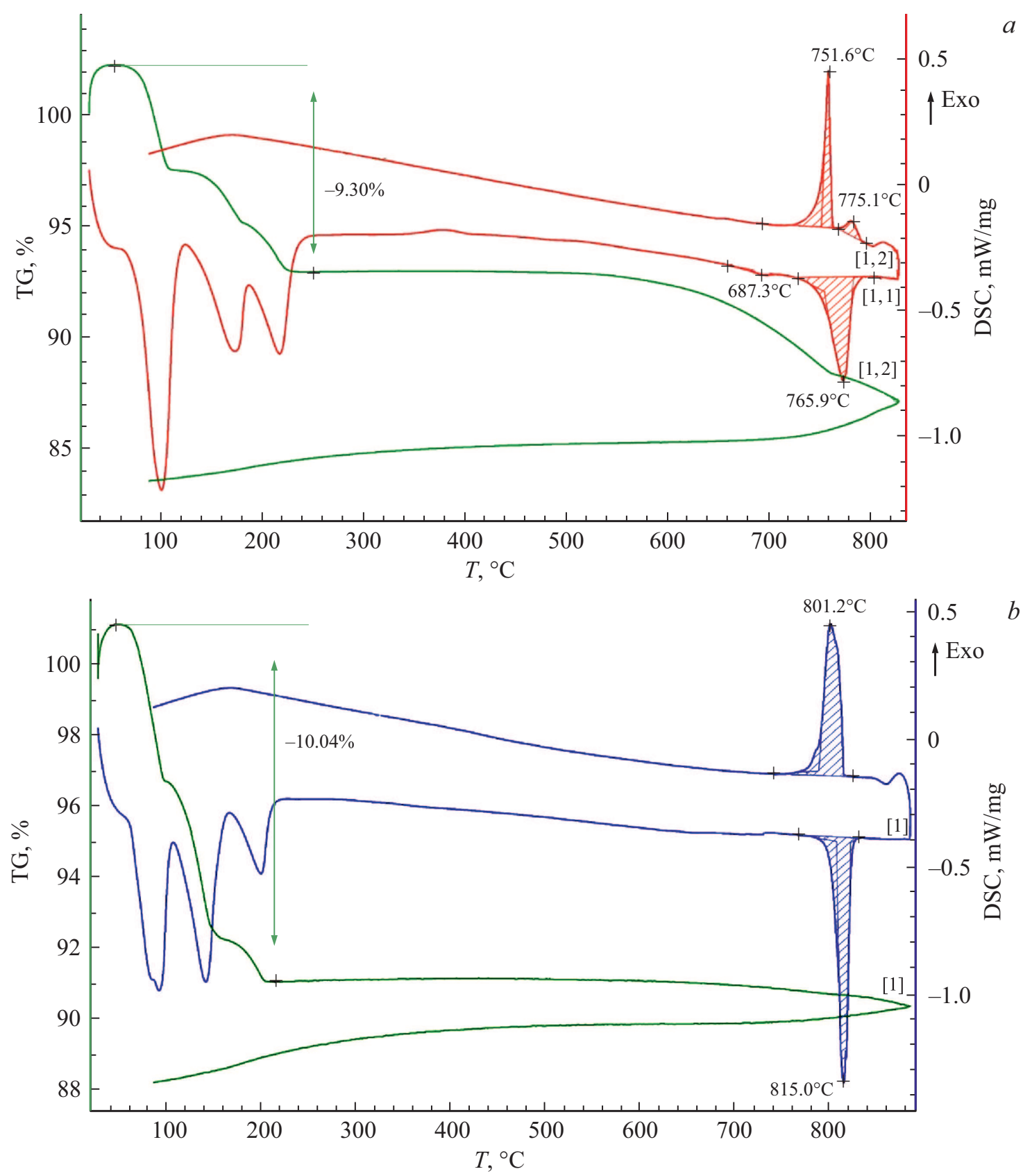

Рис. 1. Кривые дифференциально-сканирующей калориметрии и термогравиметрии: $a$ BaBrI; $b$ BaClI; $c$ SrBrI.

бария и стронция соответственно. Данные соединения плавятся конгруэнтно при стехиометрическом соотношении компонентов $1: 1 \quad\left(\mathrm{BaBr}_{2}-\mathrm{BaI}_{2}, \mathrm{BaCl}_{2}-\mathrm{BaI}_{2}\right.$ и $\mathrm{SrBr}_{2}-\mathrm{SrI}_{2}$ ). Из-за высокой гигроскопичности исходной смеси необходимо обеспечить выращивание кристаллов без контакта с внешней средой. Кроме того, во избежание нарушения стехиометрии над расплавом должна быть создана атмосфера, содержащая летучие компоненты кристаллизуемого вещества. Поэтому наиболее удобным способом кристаллизации в данном случае является метод Бриджмена, при котором шихта на протяжении процесса выращивания находится в запаянной кварцевой ампуле.
Соединения щелочно-земельных галогенидов отличаются своей гигроскопичностью на воздухе, поэтому большое внимание перед выращиванием кристаллов уделяется сушке исходного сырья. Уровни гидратации и возможные температуры дегидратации, температуры плавления и кристаллизации составов шихты устанавливались методами термогравиметрического анализа (ТГ) и дифференциальной сканирующей калориметрии (ДСК). Анализ шихты проводился на синхронном термическом анализаторе STA 449 C Jupiter (NETZSCH), который позволяет фиксировать кривые ДСК и ТГ. Такой анализ позволяет изучать фазовые переходы и получить информацию о термическом поведении образца (рис. 1). 


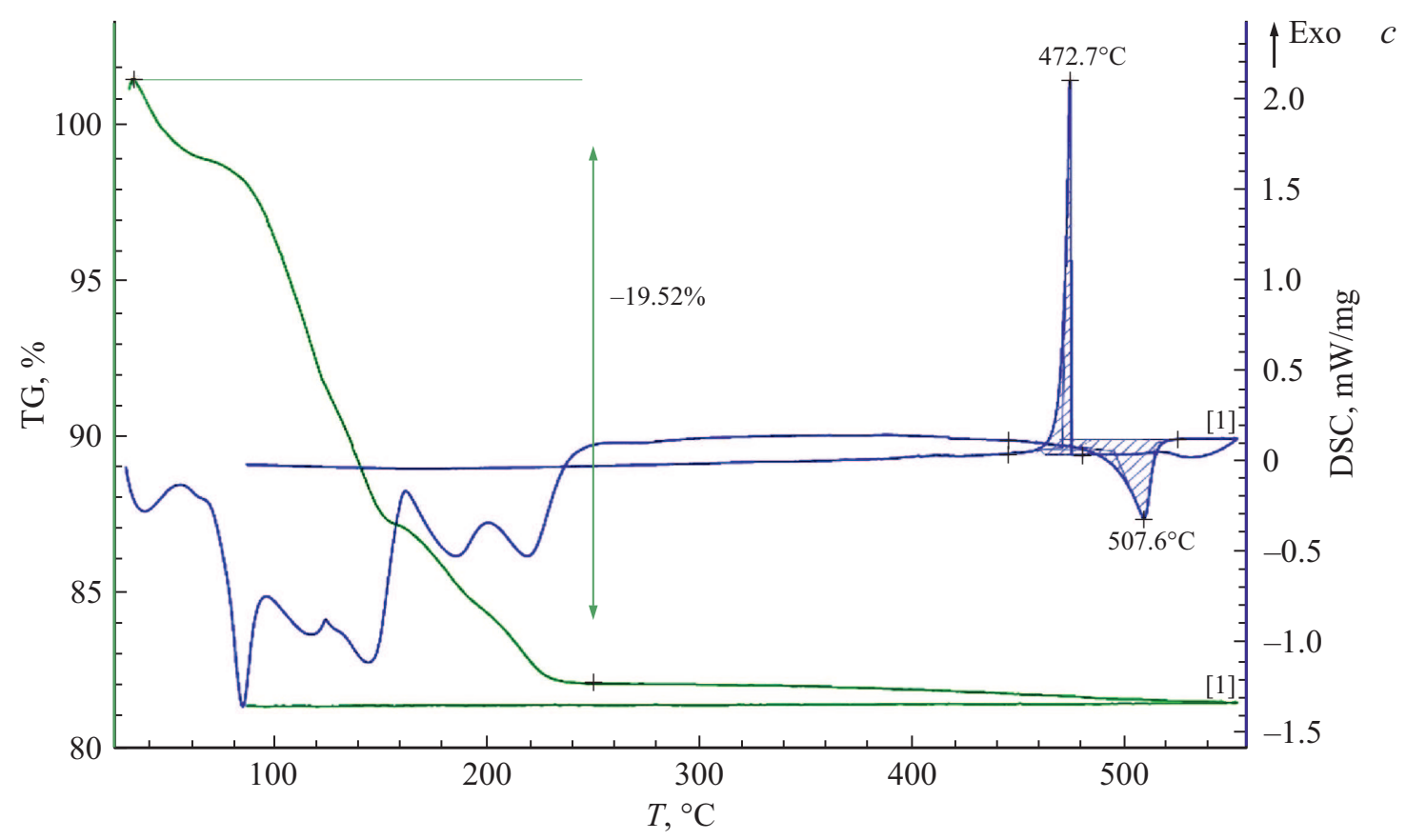

Рис. 1 (продолжсние).

На рис. 1, $а$ представлены результаты для соединения BaBrI. Потеря массы в интервале температур 50-240 $\mathrm{C}$ составляет $9.3 \%$, что соответствует трем пикам на кривой ДСК. Перед плавлением наблюдается незначительный пик при температуре $683^{\circ} \mathrm{C}$. Плавление шихты начинается при температуре $747^{\circ} \mathrm{C}$ и заканчивается при температуре $776^{\circ} \mathrm{C}$. На кривой охлаждения ДСК перед кристаллизацией также наблюдается незначительный пик при температуре $775^{\circ} \mathrm{C}$. Кристаллизация начинается при температуре $744^{\circ} \mathrm{C}$ и заканчивается при температуре $755^{\circ} \mathrm{C}$. На рис. $1, b$ представлены кривые для соединения ВaCII. По кривой ТГ видна потеря массы $10.04 \%$ в интервале температур от комнатной до $220^{\circ} \mathrm{C}$. По кривой нагрева ДСК видно, что начало плавления происходит при температуре $807.5^{\circ} \mathrm{C}$. Судя по кривой охлаждения ДСК, кристаллизация начинается при температуре $789.1^{\circ} \mathrm{C}$. На рис. $1, c$ представлены кривые для соединения SrBrI. По данным ТГ соединение теряет воду в интервалах температур $110-150^{\circ} \mathrm{C}$ и $160-220^{\circ} \mathrm{C}$, общая потеря в массе составила $19.52 \%$. Согласно кривой нагрева ДСК, температура плавления соединения составляет $507.6^{\circ} \mathrm{C}$. А согласно кривой охлаждения ДСК, температура кристаллизации составляет $472.7^{\circ} \mathrm{C}$.

На основании полученных данных дифференциальносканирующей калориметрии и термогравиметрии были подобраны режимы сушки исходного сырья и установлены температуры начала плавления и кристаллизации изучаемых соединений.

В качестве исходных материалов для приготовления шихты использовались безводные соединения квалификации ос.ч. компании ЛАНХИТ (Москва). Однако многоступенчатая предварительная просушка исходных реакционных смесей не позволяет полностью избавить- ся от кислородсодержащих примесей, которые могут служить центрами спонтанной кристаллизации и приводить к возникновению многочисленных дефектов, что в свою очередь, может способствовать растрескиванию кристалла. Поэтому следующим этапом подготовки шихты являлась фильтрация расплава через фильтр, изготовленный из кварцевой крупки с размером гранул порядка 400-450 $\mu \mathrm{m}$. Прошедшая высокотемпературный отжиг крупка активно адсорбирует на своей поверхности кислородные и водородные примеси. После процедуры фильтрации даже визуально отмечается повышение прозрачности расплава и отсутствие хлопьев, вызванных оксидными и гидроксидными включениями.

Для проведения фильтрации расплава исходных соединений была разработана конструкция кварцевой системы, состоящая из двух рабочих объемов, разделенных тонкой кварцевой трубкой. Верхний объем используется для предварительной сушки шихты. В нем установлен кварцевый фильтр, пройдя через который расплавленное сырье стекает в нижний объем системы. После осуществления фильтрации, нижний объем отпаивается и помещается в ростовую установку для дальнейшего выращивания монокристалла. Процедуры сушки шихты и фильтрации расплава, вплоть до момента отпаивания ампулы, происходят при постоянном вакуумировании. Выращивание кристаллов производилось из расплава вертикальным методом Бриджмена в вакуумированных кварцевых ампулах диаметром 10-30 mm. Для оптимизации процесса кристаллообразования было опробовано несколько форм ампул с различной конфигурацией носовой части. Установка для выращивания кристаллов имеет двадцать нагревательных модулей и оснащена шестнадцатью термопарами, что позволяет моделиро- 
вать температурный градиент со сложным профилем. Управление осуществляется с ПК посредством специального программного обеспечения.

Одной из наиболее трудоемких задач получения кристаллов данного типа является подбор оптимального режима выращивания. После кристаллизации расплава полученный монокристалл может быть деформирован из-за разности коэффициентов термического расширения вещества и стенок ампулы. В результате в слитке могут возникать дислокации, блоки и другие дефекты, приводящие к растрескиванию кристалла. Поэтому были подобраны „мягкие“ параметры выращивания с небольшими градиентами температур (не более $4^{\circ} \mathrm{C} / \mathrm{cm}$ ) и скоростью около $1 \mathrm{~mm} / \mathrm{h}$. После прохождения рабочей зоны температурного градиента ампула охлаждалась со скоростью $5-10^{\circ} \mathrm{C} / \mathrm{h}$ для предотвращения растрескиваний и накопления напряжений в кристалле.

Из-за гигроскопичности галоидных материалов необходимо применять специальные методы для защиты образцов кристаллов от воздействия воздуха. После извлечения кристаллов из ампулы их сразу помещали в пластиковые контейнеры, заполненные вазелиновым маслом. Извлечение и обработка кристаллов происходили в сухом перчаточном боксе. Для спектральных исследований выпиливались либо монокристаллические пластинки диаметром 10-15 mm и толщиной $2-3 \mathrm{~mm}$, либо кубические образцы $10 \times 10 \mathrm{~mm}$.

Исследование структуры выращенных монокристаллов проводилось методами порошковой и монокристаллической рентгеновской дифракции на дифрактометрах D8 ADVANCE и X-8 APEX (Bruker AXS). Рентгенофазовый анализ использовался для определения состава и контроля стехиометрии полученного соединения. Для монокристаллов ВаCІІ были впервые определены кристаллографические параметры и результаты этих исследований были представлены в работе [7].

Для активирования кристаллов BaBrI и $\mathrm{SrBrI}$ европием использовалось соединение $\mathrm{EuBr}_{3}$, а для кристаллов $\mathrm{BaClI}-\mathrm{EuCl}_{3}$. Из-за схожести ионных радиусов и зарядов ионы европия замещают ионы бария в BaBrI и BaClI, и места стронция в SrBrI. Чтобы оценить степень вхождения примеси $\mathrm{Eu}$ в решетку кристалла BaBrI, проанализировали несколько образцов с концентрациями $\mathrm{Eu}$, соответствующими $0.01 \%, 0.05 \%, 0.1 \%$, $5 \%$ и 7\%. Определение содержаний аналита выполнено методом масс-спектрометрии с индуктивно связанной плазмой (ИСП-МС) из растворов, полученных после растворения кристаллов и отделения бария как основного мешающего элемента. Измерения проводили на масс-спектрометре высокого разрешения Element 2 (Finnigan MAT, Германия). Кроме того, два кристалла были также проанализированы методом рентгенофлуоресцентного анализа (РФА), не требующего предварительной химической пробоподготовки.

Полученные результаты показали более низкий уровень содержания европия по сравнению с вводимыми добавками. При этом с увеличением концентрации вводимых добавок наблюдалось увеличение интенсивности

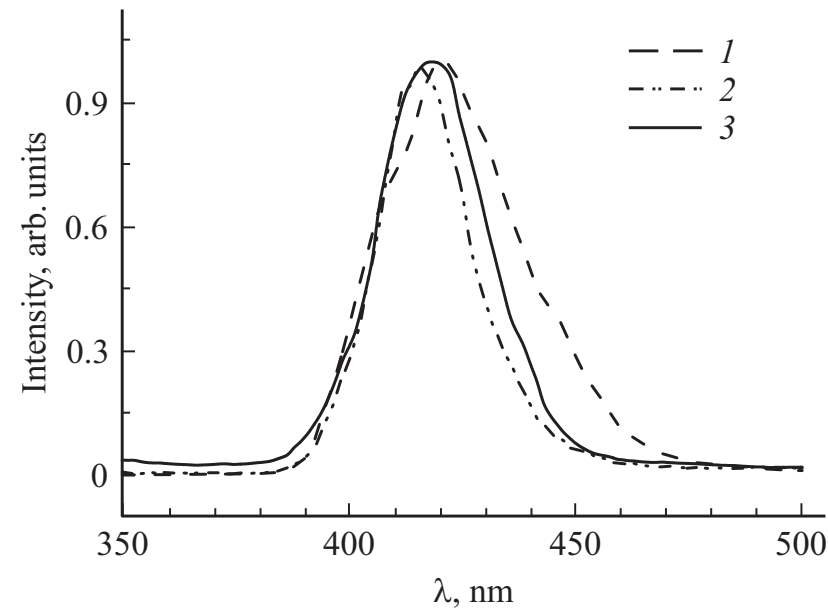

Рис. 2. Нормированные спектры рентгенолюминесценции кристаллов, измеренные при комнатной температуре: BaCli:0.1 mol.\% Eu (1), BaBrI:0.1 mol.\% Eu (2) и SrBrI: $0.1 \mathrm{~mol} \% \mathrm{Eu}(3)$.

сигналов Eu в растворах. По двум принципиально разным методам получены близкие значения содержания Eu: $3.1 \%$ (ИСП-МС) и 2.1\% (РФА) - для образца с добавкой 7\% $\mathrm{Eu}$; а также $0.003 \%$ (ИСП-МС) и $<0.01 \%$ (РФА) - для образца с добавкой $0.05 \% \mathrm{Eu}$.

Более низкие значения содержания европия по сравнению с рассчитанными концентрациями вводимых добавок могут являться результатом потерь, происходящих в процессе выращивания кристалла. Можно предположить, что для кристаллов BaClI и $\mathrm{SrBrI}$ характер вхождения $\mathrm{Eu}$ будет аналогичным.

Однако, несмотря на более низкие фактические концентрации европия по сравнению с изначально вводимыми в шихту, исследуемые кристаллы показывают высокий световой выход люминесценции (таблица).

Были проанализированы спектры рентгенолюминесценции выращенных кристаллов. Они были получены при использовании рентгеновской трубки 10-Л-01 в режиме $50 \mathrm{kV}, 1 \mathrm{~mA}$. Свечение регистрировалось монохроматором МДР-2 с дифракционной решеткой 1200 lines/mm и фотомодулем Hamamatsu H6780-04, paботающим в режиме счета фотонов.

В спектрах рентгенолюминесценции исследуемых кристаллов (рис. 2) наблюдаются широкие полосы с пиками в диапазоне от $415 \mathrm{~nm}$ до $418 \mathrm{~nm}$ в зависимости от типа кристалла (таблица). Интенсивность полос зависит от концентрации европия в образцах. Положение пика в спектре рентгенолюминесценции этих кристаллов также свидетельствует о вхождении в кристаллическую решетку европия в двухвалентном состоянии с характерными для него переходами $5 d-4 f \quad[6,8]$. Двухвалентный европий замещает ион бария или стронция. Изменение положения максимума в спектре люминесценции $\mathrm{Eu}^{2+}$ в зависимости от типа кристалла обусловлено изменением окружения - расстоянием между катионом (Ba или $\mathrm{Sr}$ ) и анионами $(\mathrm{Br}, \mathrm{I}, \mathrm{Cl})$. 
Основные сцинтилляционные свойства выращенных кристаллов

\begin{tabular}{c|c|c|c|c}
\hline Кристалл & $\begin{array}{c}\text { Световыход } \\
\text { (photons/meV) }\end{array}$ & $\begin{array}{c}\text { Пик } \\
\text { свечения, } \\
\mathrm{nm}\end{array}$ & $\begin{array}{c}\text { Время } \\
\text { затухания, } \\
\mathrm{nc}\end{array}$ & $\begin{array}{c}\text { Ширина } \\
\text { запрещенной зоны } \\
\mathrm{Eg}, \mathrm{eV}[7,8]\end{array}$ \\
\hline $\mathrm{BaBrI}: 5 \% \mathrm{Eu}$ & 74000 & 415 & 400 & 5.6 \\
$\mathrm{BaClI}: 5 \% \mathrm{Eu}$ & 25000 & 421 & 450 & 6.3 \\
$\mathrm{SrBrI}: 0.1 \% \mathrm{Eu}$ & 15000 & 418 & 320 & 6.0
\end{tabular}

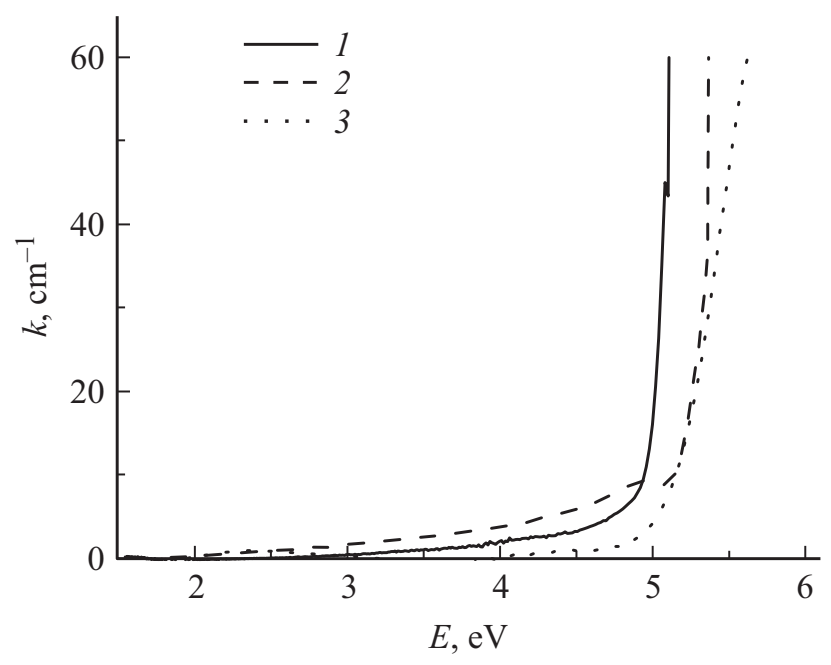

Рис. 3. Спектры поглощения номинально беспримесных кристаллов $\mathrm{BaBrI}(1), \operatorname{SrBrI}(2), \mathrm{BaClI}(3)$.

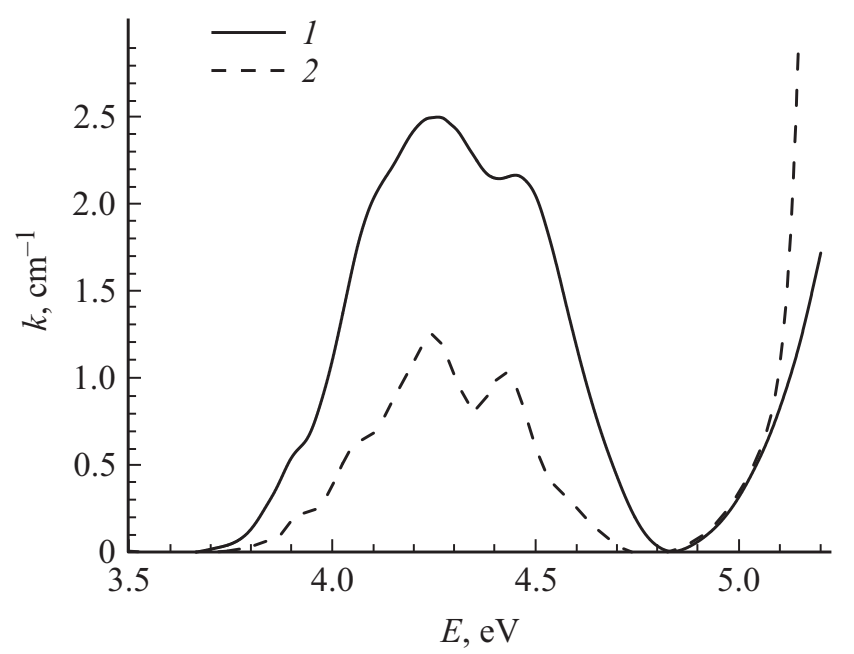

Pис. 4. Спектры поглощения кристаллов BaClI:0.1 mol.\% Eu (1) и $\mathrm{BaBrI}: 0.05$ mol.\% Eu (2).

По спектрам рентгенолюминесценции был оценен световыход выращенных нами кристаллов по сравнению со световыходом широко применяемого сцинтиллятора $\mathrm{CaF}_{2}: \mathrm{Eu}(21500$ photons/MeV). Для этого были изготовлены образцы одинакового размера. Интегральная интенсивность рентгенолюминесценции исследуемых кристаллов сравнивалась с интегральной интенсивностью люминесценции образца $\mathrm{CaF}_{2}$ : $\mathrm{Eu}$ с известным световым выходом. Так как свечение всех исследуемых образцов находится в одной области, то корректировка на спектральную чувствительность не проводилась.

Спектры поглощения исследуемых кристаллов были получены с помощью спектрофотометра Lambda 950.

В спектре поглощения неактивированных кристаллов никаких пиков не наблюдается (рис. 3). Фундаментальный край поглощения находится в области 5.5-6 eV, что соответствует ширине запрещенной зоны исследуемых кристаллов, определенной ранее в работах [7,9]. При активации исследуемых кристаллов европием в спектрах поглощения появляется двойной пик в области $4-4.5 \mathrm{eV}$. Эти пики связаны с переходами $4 f 7-5 d 14 f 6$ в ионах европия. По краю оптического поглощения была оценена ширина запрещеннной зоны кристаллов (таблица). Необходимо отметить, что на спектрах и в таблицах указаны концентрации европия, вводимые в шихту перед выращиванием кристаллов. Как было показано ранее, фактически найденное содержание европия в кристаллах ниже.

\section{3. Заключение}

В работе представлена методика выращивания кристаллов щелочно-земельных галогенидов $\mathrm{BaBrI}, \mathrm{BaClI}$ и $\mathrm{SrBrI}$ методом Бриджмена. Из-за высокой гигроскопичности соединений необходимо уделять большое внимание предварительной подготовке шихты для выращивания кристаллов. В связи с этим был проведен анализ шихты методами термогравиметрического анализа и дифференциальной сканирующей калориметрии. На основании полученных данных были подобраны режимы сушки исходных смесей и установлены температуры плавления и кристаллизации изучаемых соединений. С целью устранения кислородсодержащих примесей, которые могут служить центрами спонтанной кристаллизации, проводилась фильтрация расплава через кварцевый фильтр. Такая процедура способствует увеличению оптического качества выращиваемых кристаллов. Методами ИСП-МС и РФА была оценена фактическая концентрация европия, вошедшего в кристаллы BaBrI. Полученные результаты показали более низкий уровень содержания европия в кристаллах по сравнению с вводимыми концентрациями активатора в шихту. Несмотря на этот факт, в выращенных кристаллах наблюдается 
высокий световой выход люминесценции и прослеживается явная корреляция между вводимой в шихту концентрацией европия и интенсивностью люминесценции. Требуются дополнительные исследования по изучению факторов, влияющих на вхождение редкоземельных примесей в структуру выращиваемых кристаллов. Выявление этих закономерностей могут способствовать разработке новых технологий, направленных на увеличение сцинтилляционной эффективности кристаллов щелочноземельных галогенидов.

\section{Список литературы}

[1] M. Nikl, A. Yoshikawa. Adv. Opt. Mater. 3, 4, 463 (2015).

[2] A.V. Gektin, A.N. Belsky, A.N. Vasil'ev. IEEE Transact. Nucl. Sci. 61, 1, 262 (2014).

[3] E. Bourret-Courchesne, G. Bizarri, R. Borade, G. Gundiah, E. Samulon, Z. Yan, S. Derenzo. J. Cryst. Growth 352, 1, 78 (2012).

[4] M. Janecek, R. Borade, S.E. Derenzo. Nucl. Instrum. Meth. Phys. Res. A 659, 1, 252 (2011).

[5] D.R. Onken, R.T. Williams, D. Perrodin, T. Shalapska, E.D. Bourret, A. S. Tremsin, S.C. Vogel. J. Appl. Crystallogr. 51, 2, 498 (2018).

[6] G. Gundiah, G. Bizarri, S.M. Hanrahan, M.J. Weber, E.D. Bourret-Courchesne, S.E. Derenzo. Nucl. Instrum. Meth. Phys. Res. A 652, 1, 234 (2011).

[7] R. Shendrik, A. Shalaev, A. Myasnikova, A. Bogdanov, E. Kaneva, A. Rusakov, A. Vasilkovskyi. J. Lumin. 192, 653 (2017).

[8] E.D.Bourret-Courchesne, G. Bizarri, S.M.Hanrahan, G. Gundiah, Z.Yan, S.E.Derenzo. Nucl. Instrum. Meth. Phys. Res. A 613, 1, 95 (2010).

[9] A. Shalaev, R. Shendrik, A. Myasnikova, A. Bogdanov, A. Rusakov, A. Vasilkovskyi. Opt. Mater. 79, 84 (2018).

Редактор К.В. Емцев 